\title{
Ethical Considerations when Involving Older People in Public Service Participation Processes
}

\section{Peter Scourfield and Sarah Burch}

Peter Scourfield is Senior Lecturer in Social Policy, and Sarah Burch is Principal Lecturer in Social Policy, both in the Faculty of Health and Social Care, Anglia Ruskin University, Cambridge, UK.

Correspondence to: Peter Scourfield, Faculty of Health and Social Care, Anglia Ruskin University, East Road, Cambridge, CBI IPT, UK; E-mail: peter.scourfield@anglia.ac.uk

In the United Kingdom, as in many other countries, New Labour governments have heavily promoted different forms of 'service-user involvement' in decision making about public services. The current orthodoxy would appear to be that involvement activities carry with them de facto benefits that are both affirmative and empowering. However, relatively little research has been carried out into considering the real impact (emotional or otherwise) of involving citizens in such processes. In this paper, the findings from a small-scale qualitative study led the authors to reflect that when outcomes of consultation are undesired and that when the precise role of those involved is left unclear in terms of purpose, responsibility and accountability, people can be left with powerful, often uncomfortable, feelings. The ethical dimensions of involving people without adequate, prior preparation or ongoing support are discussed, with suggestions made as to how public organisations can take an ethically sound approach to participation. Drawing on research ethics, and informed by the ethics of care, methods through which the potentially harmful effects of involvement can be mitigated are proposed.

Keywords Older People; Service-user Involvement; Participation; Ethics; Reference Group; Ethics of Care

\section{Introduction}

New Labour's 'modernisation' agenda for public services in the United Kingdom has been in operation for over 10 years. A central plank of this agenda has been the requirement that services be more responsive to the demands and requirements of both service users and potential service users. Over the past decade, therefore, older people, as a major user group, have been actively recruited into various forms of participative endeavour. In order to inform decision making and evaluate their policy and practice, those responsible for commissioning and providing public services have engaged the older public in a diverse range of forms of user participation (such as panels, steering groups, reference groups, partnership boards and users' forums) to supplement more traditional methods such as surveys and 'complaints and comments' procedures. Programmes such as 'Better Government for Older People' have helped ensure that the principle of 'listening to older people' is now embedded in public services. In recent years, public bodies, whether in the statutory or independent sector, have therefore been expected to make greater and greater efforts to secure the involvement of older people in a diverse range of consultative and participative processes. There is an international context. 'Participation' has been made one of the United Nations' 'Principles for Older Persons' since the 'International Plan of Action on Ageing' was endorsed by the UN General Assembly in 1982 (United Nations 2009a). Initiatives such as the 'United Nations Programme on Ageing' (United Nations 2009b) indicate that the drive to enable older people's involvement is not confined solely to the United Kingdom. The challenge of making the participation agenda work effectively for older people has now, therefore, become a matter of global significance.

The current orthodoxy would appear to be that, whatever the outcome or whatever the issue, the involvement of older people is a process that carries with it de facto benefits that are both affirmative and empowering. Such processes have come to be regarded as unquestionably and intrinsically positive. From this it is too easily assumed that older people always experience the processes of consultation and involvement positively. However, relatively little 
research has been carried out into considering the real impact (emotional or otherwise) of involving older people in such processes.

In this paper, the authors draw on the findings from a small-scale exploratory case study which provided insights into how one particular group of older people experienced the participation process. As with many such studies, the number of participants was small and its exact nature hard to replicate and thus generate a larger evidence base. However, some particularly revealing insights and findings did emerge, which provide a basis for ethical reflection of wider interest. The study has led the authors to surmise that when outcomes of consultation are undesired and that when the precise role of those involved is left unclear in terms of purpose, responsibility and accountability, older people can be left with powerful, often uncomfortable, feelings.

Arguably, members of the public invited into different participation activities should be regarded in the same way as members of the public invited to participate in research. The ethical dimensions of involving older people without adequate, prior preparation or ongoing support are discussed, with suggestions made as to how public organisations can take an ethically sound approach to participation. Drawing on research ethics, and informed by the ethics of care, various methods through which the harmful effects of involvement can be mitigated are proposed.

\section{Background}

Since 1997, New Labour's project of modernisation in the United Kingdom has centred on ideas about active citizenship and new modes of democratic engagement combining to produce what has been described as 'participative governance'. Concerns about legitimacy, a 'democratic deficit' and the need to shift power and responsibility to the 'citizen' have led to the emergence of a range of new deliberative forums and democratic processes. A key aim of these processes has been to ensure that service users are represented in decision-making processes that affect them.

In 1998, the 'Better Government for Older People' initiative was introduced 'to improve public services for older people by better meeting their needs, listening to their views and encouraging and recognising their contribution' (Cabinet Office 2005). The following year, the Local Government Act 1999 created Best Value authorities with a duty to consult all service users or their representatives. By 2005, Simmons and Birchall were able to observe:

In recent years, policy-makers and consumer groups have therefore called for the more
intensive participation of service users in the governance and delivery of a range of public
services. In response, service agencies have engaged in evaluating their own policy and
practice, and there has been a move towards creating a range of alternative forms of user
participation (such as consumer councils, panels and forums, and/or participation in agencies'
governing structures) to supplement more traditional methods. Together, these developments
lead Beresford (2001:267) to assert that 'there has never been so much political and policy
interest expressed in participation, across so many fields'. (2005, p. 261)

It could be assumed that, in whatever form it takes, 'participation' is inherently positive and that the engagement of older people in decisions that affect them is both desirable and beneficial to all concerned. Indeed, such processes are often described in policy statements as putting older people 'in control', putting older people 'at the centre' or 'in the driving seat'. The statement below is indicative:

By putting older people 'in control', and giving them a say in how services are shaped and delivered, longevity can be positioned as a result of good, effective care and support ${ }^{\star}$ to live longer is an achievement, not a burden. (Counsel and Care 2007, p. 5)

Here, older people's involvement is linked explicitly to positive outcomes. Implicit in this kind of statement is the suggestion that the act of being involved is also inherently positive. Theories of public participation (e.g. Arnstein's well-known 'ladder of participation') suggest that there are links between the degree of say or control that people have in influencing services that affect them and the degree of genuine empowerment they experience. Arnstein 
posited that there are eight rungs on the ladder of participation. The bottom rungs of the ladder are 'manipulation' and 'therapy' which are, in essence, nothing more than the illusion of participation, with no notice taken of those involved. Rungs three ('informing'), four ('consultation') and five ('placation') all allow for a greater degree of 'tokenistic' involvement. However, it is only further up the ladder where increasing degrees of real decision-making 'clout' are in evidence. For Arnstein, citizens at rung six ('partnership') are able to negotiate and engage in trade-offs with traditional power holders. At the top, rungs seven ('delegated power') and eight ('citizen control') are when citizens could be said to assume, more or less, full power over decision making and resources. Arnstein states:

There is a critical difference between going through the empty ritual of participation and having the real power needed to affect the outcome of the process. (1969, p. 216)

What seems to be apparent is that, in many of the activities that are undertaken under the banner of 'participation', it is seldom made explicit where exactly on the ladder those involved are expected to operate. This is not necessarily through the desire to manipulate people, neither to simply placate them nor to create tokenistic forms of involvement. Rather, it is often through the well-intentioned desire to involve older people, because it is considered to be selfevidently a 'good thing'. For providers or commissioners of public services in the early twentyfirst century it has become established as the received wisdom that the good provider/commissioner involves service users in some shape or form. This impulse springs from an awareness (although not always an understanding) of a range of powerful and overlapping discourses, including choice, citizenship, inclusion, modernisation, civic renewal and 'the good society', that have emerged in the United Kingdom since the 1980s. However, problems are likely to emerge when the 'involvers' and the 'involvees' have different ideas or expectations about what precise rung those involved are on, how much control and therefore how much responsibility they have in decision_ making.

In this paper, we use the case study of a service-users' Reference Group which had been created by a voluntary organisation for older people in response to the need to close a drop-in centre, to examine more deeply what the effects of 'participating' have on those who take part. The fact that the organisation running the drop-in centre thought to involve older people could be considered a positive move. However, the failure to agree and clarify the powers, roles and responsibilities fully for those involved seems to have inadvertently created a noticeable degree of 'ill-being' in the process of participation rather than well-being. The fact that involvement activities might produce negative consequences for unsuspecting participants raises an ethical challenge for public organisations which is not always fully appreciated. The challenge is how to ensure that participants are not exposed to any unnecessary harm from their experiences.

\section{The Drop-in Centre under Threat}

The drop-in centre for older people was located in the centre of a town with a population of approximately 100,000 and had been open in one form or another since 1978. However, it had never been financially secure. To help keep it going, an older people's voluntary organisation had taken over the running of the centre in 2000. Its main function, latterly, was to provide a friendly environment for older people to come in and meet others, have a cup of tea and a snack. There was no membership and no fee* informality was the watchword. There was one paid member of staff who both organised the catering arrangements and greeted people and made them feel welcome. In 2005, the centre came under threat of closure because it was running an annual deficit that was no longer sustainable. In view of this, the older people's voluntary organisation decided to surrender the lease from the end of September that year. In pursuing this course of action, however, the voluntary organisation had also decided to undertake an independent evaluation in order to best determine how the core of the service might be provided in other ways. An evaluation of users' views took place in May 2005 and established that the centre was 'a lifeline' for older people. Some members of the drop-in centre organised a 500-signature petition which was presented to the City Council in July 2005. Following a feedback meeting on the evaluation, it was decided that a user-led initiative steered by a 'Reference Group' comprising 10 older people would undertake to plan a new open-access centre for older people in the town. There was no 
formal selection procedure to join the Reference Group. The particular older people concerned mainly put themselves forward as representatives of both the drop-in centre and as potential users of an alternative, open-access centre for older people. Word of mouth seems to have played a significant part in who eventually joined. It later became apparent that some had to be more strongly 'persuaded' than others to join the group. Whilst they came from a variety of professional and social backgrounds, joining such a Reference Group was a new experience for all of them.

However, for the drop-in centre, there was no final 'stay of execution'. By the time the centre finally closed in March 2006 no suitable alternative had been found, leaving it uncertain whether anything would replace it in the foreseeable future. This outcome emerged despite expressions of support, in principle, from potential funders such as the local PCT and the local council and a considerable amount of effort from the Reference Group. The drop-in centre had closed without anything to replace it. The following extracts from a briefing statement made by the Reference Group in December 2005 give a flavour of how the closure was received:

It's very important for a lot of elderly, particularly for those on the state pension and those who live alone.

Great disappointment for lots of people.

Without the [drop-in] centre many lonely old folk will have no human contact, no chance to talk to others, will become even more lonely, their health will suffer and they [will] become a drain on the health service. Cannot the powers that be see this or are they totally blind to the needs of older folk? What a dreadful outlook for this city of ours.

The current situation is wrong both in its total abrogation of its responsibilities for those who are elderly and lonely; but also in the implied hypocrisy of the lip service tributes paid to this wartime generation in September of this year.

The Reference Group had therefore not been successful in achieving its objectives. Although, throughout the whole process, what exactly the objectives were, in the minds of the different Reference Group members, was unclear. For some, the purpose was more to campaign to keep the existing drop-in centre open whilst, for others, it was to ensure that a suitable alternative be found. For those interviewed, both sets of objectives seem to have been pursued at the same time. These and other ambiguities emerged from the research study that followed.

\section{The Study}

The study developed from the desire of the chief executive of the older people's voluntary organisation to learn from the whole episode. It, too, was unhappy about the way the exercise had gone. After discussion between the chief executive and the university researchers it was decided to help facilitate this aim by interviewing the members of the Reference Group. The research was designed as an inductive, qualitative study, the conceptual framework being informed by social constructionism, that is to say a view that understandings of the world are constructed via language and descriptions which are in themselves constructed (Potter 1996). As such, it was felt to be an appropriate framework within which to explore how the participants constructed and made sense of the reality of being a member of the Reference Group. These understandings were explored through in-depth, semi-structured interviews with the members of the Reference Group. The broad research questions were: 'What was it like for them being a member of the Reference Group?', 'What decided them to participate in this process?', 'Would they do it again?' and 'What would they have liked to have been done differently?'

The sample was small and, therefore, as with qualitative research in general, claims to generalisability are questionable (Lewis \& Ritchie 2003). Nevertheless, there was a broader rationale for conducting the study. Apart from gathering specific insights into what it is like to participate in such a process from the participants' point of view in this case, it was also felt that there could be lessons to be learned as far as how other similar reference groups are 
recruited and supported before, during and after the process. Also, strategies on how to prevent drop-out from such groups might be developed.

\section{Sample}

Of the ten original members of the Reference Group, five eventually agreed to participate in the research. There were three women and two men. All were aged in their $70 \mathrm{~s}$ or $80 \mathrm{~s}$.

\section{Method}

Interviews took place in respondents' homes and were taped and transcribed. Analysis was conducted via processes of open and theoretical coding with the help of CAQDAS software (Nvivo). The coding was informed by the constant comparative method (Glaser \& Strauss 1967) and took place as soon as the first interviews were conducted, in order that emerging issues of interest might guide subsequent interviews. Using this method it was possible to identify several themes.

\section{Findings}

Two broad themes emerged that are relevant to the focus of this paper. The first concerns matters of representation. There was uncertainty whether members of the reference group felt their role was to represent all older people of the area as potential service users or whether they were to represent existing users of the drop-in centre. Individual respondents' feelings about their role in representation seemed to be influenced by how they related to their identities as older people and as users of the drop-in centre. In this area, there was a particular tension about whether they saw themselves as acting altruistically for others or in their own interests. At times, participants talked as if they were a part of the user group, for example by using the first-person 'we', and at other times they referred to 'old people' or 'pensioners' as if they were distancing themselves from such groups.

Secondly, it was interesting that, despite promptings, interviewees were noticeably more reluctant to talk about their role in the Reference Group than they were to talk about either the many perceived benefits of the drop-in centre or of some of the problems facing older people. There was much more comment on processes surrounding the Reference Group rather than on how it carried out its work. There seemed to be a number of uncertainties surrounding the remit of the group. Whilst some mentioned the role of offering information on what older people as a service-user group may need, a more common perception seemed to be that they were a campaign group to save the drop-in centre. Linked to this, the precise relationship between the Reference Group and the voluntary organisation that had set it up was also difficult to determine from the responses. At times, it appeared as if the Reference Group was in opposition to the voluntary group, for example in the way they discussed the issue with the local media, and at other times, group members seemed to be almost in some form of ambassadorial role* for example when meeting with council members. The Reference Group also made a video, although what the exact purpose of this was is unclear. There was an occasion when the voluntary organisation and the Reference Group were seemingly acting as partners, for example on a fact-finding visit to a multi-purpose centre elsewhere in the country. In terms of Reference Group activities, members mentioned that they were doing tasks and carrying out a role that was entirely new to them, which they greeted with some apprehension. The following comments from one of the male members, who had been asked to speak at a formal council meeting, are indicative:

To my horror, after five minutes or so, the wall just opened, and in front of me, was this great council meeting...

... with two rows of councillors, as far as the eye seemed to be able to see and a chairwoman up the far end. I can tell you it was quite a frightening experience...

.... a chair at the top where I was supposed to sit. I didn't, I stood up there on a silly little curb like a fool. I was told you've got five minutes to present this petition. There will then be no statements from councillors, just questions. 
In general, though, members were positive about the activities themselves, but perceptions were tainted by the outcome for the drop-in centre, which many interpreted as a personal failure. There was also unhappiness about the end of the role and confusion about whether it had ended.

Each participant had his or her own individual responses and reactions to both the process of being in the Reference Group and to the closure of the drop-in centre. However, the male members, in particular, vocally expressed considerable anger, bitterness and disappointment, as if they had lost a particular battle and let both themselves and others down. Whilst it was apparent that all those interviewed had made a significant emotional investment in the Reference Group, the male members seemed to take it more personally, using words like 'betrayed', 'cheated' and 'let down' about the way they had been treated by the voluntary organisation, the local authority or PCT. The female participants also felt that the older users of the centre had been let down, facing possible social isolation and loneliness as a consequence. However, whilst they expressed feelings of disappointment and regret about the closure, they were less inclined to blame themselves explicitly for this outcome. It is, perhaps, unsurprising that the loss of the centre caused strong feelings. However, overlaying the feelings about the closure and the failure to find a replacement were many comments that indicated a noticeable lack of clarity about quite what it was that they were expected to do. The group was not clear what the exact scope and nature of its powers, duties and responsibilities were. This was not just in terms of whether the real objective was saving the centre or finding an alternative solution. When asked what being in the group involved, a female interviewee replied:

...well it really involved, I don't, it didn't, ahm, I mean it didn't involve er, very much really, I mean some people talked, went off to try and find other places. There was this discussion that we should be doing much more, you know, much more activities and this was the way to get money...

There was also confusion about to what extent they were an advisory group, a campaign group or a problem-solving group in a more practical sense. Interviewees mentioned one member of the Reference Group who, apparently, had taken it upon himself to spend hours every day walking around the town looking for suitable premises. These extracts from one interview convey some of the feeling surrounding this:

....and erm, then we took it from there. And er, there was one chap, 'Jim', he, he went round gathering information about all the various places in [the town] where it might be possible to have another place. But, most of them were nowhere near the city centre...

...so, you know, it's sad, but er, he's dropped out now and um, we couldn't do nothing about that...we also discussed plans and things. But the meeting generally broke up with nothing conclusive...nothing conclusive at all.

However, none of those interviewed had any firm idea of how much money was available to spend or what the exact specification for any new premises was. The man in question was reported to be too upset and angry to take part in the study. Indeed, one of the female participants needed no little persuasion to take part, believing that the research was a waste of money which could be better spent towards services for older people. This pointed to another area of uncertainty; that of whether they were speaking for and representing themselves as individual members or as representatives of a larger constituency, whether that be the other drop-in centre users or the older population of the area at large. It emerged that some people had actively canvassed the opinion of others, often rallying support for their views, whilst others were more prepared to express their own opinions. Often, people would express their own opinions and venture to claim to know what other old people wanted.

Lastly, the research revealed that the members of the group were still thinking and acting as if the Reference Group was still ongoing. There had been no formal bringing of the episode to a close. The fact that the drop-in centre had closed and that no alternative had been found added to the feeling of unfinished business expressed by many interviewees. A sub-group continued to meet but with more of a social agenda rather than any other specific purpose. This lack of closure almost certainly led to some of the group continuing to ruminate in ways 
hat caused them unhappiness for longer than was necessary. One of the male interviewees kept a scrapbook of cuttings relating to the centre's closure, mainly from the local press. $\mathrm{He}$ also pointed to copies of quite angry letters he had sent to the various authorities including the chief executive of the voluntary organisation whom he said he still felt let down by. On the other hand, one of the female interviewees thought that the chief executive was 'a splendid person'. In general, all the interviewees felt that they had made considerable efforts but that they had failed.

These particular findings from the study can be related to issues that have emerged in the growing literature on older people and the participation agenda (e.g. Barnes 2005; Barnes et al. 2007; Callaghan \& Wistow 2008). A common challenge is to establish the extent that participants can legitimately represent a wider constituency of often conflicting interests. There is another relevant broad area of literature, in the sphere of occupational health, that has pointed to the link between role confusion (usually at work) and feelings of stress and emotional disturbance (e.g. Cooper \& Dewe 2004; Fontana 1989; Fairbrother \& Warn 2003). The uncertainty about role and responsibilities had operated on many levels and could be seen to be playing out in the different participants' responses in the interviews. Although the interviews took place several months after the closure of the drop-in centre, feelings of anger, regret, blame (of self and others) and frustration were evidently still running high.

\section{Ethical Considerations}

Many writers have explained how older people require support and encouragement in order to participate fully in involvement activities such as panels, steering groups and other forums. It is argued that in order to build social capital effectively and capture diversity, those seeking to involve older people need to address and overcome a range of physical, cultural, attitudinal and economic barriers, often using non-traditional methods (Tetley et al. 2003; Postle et al. 2005; Callaghan \& Wistow 2008). The formalities of traditionally run public meetings serve to institutionalise and perpetuate power imbalances, favouring those whose habitus (Bourdieu 1984) permits them to be more at home in such settings and disadvantaging those who may lack the cultural capital, confidence and necessary communicative competence to take effective part. Alternative strategies such as the use of storytelling (Barnes 2005) or even 'digital lobbying' (Gwent Association of Voluntary Organisations 2007) have been developed. However, it is unusual to read about the feelings (negative or otherwise) that may result once older people have been encouraged to participate. The case study revealed that participating in the Reference Group had caused its members a variety of unwelcome emotions, including anger, bitterness, self-doubt, frustration, a sense of failure, even shame. Unless every act of involvement has a positive outcome (which is highly unlikely), then such feelings are bound to be produced in some shape or form. Even where outcomes are more satisfactory than that reported in this study, it is still likely that individuals might be upset by the process, for example where conflict has taken place or when it has touched on difficult personal issues. This raises critical questions for involvers about how to plan for and mitigate the effects of involvement initiatives that prove to be unsatisfactory.

It is now obligatory when involving people as research subjects that ethical procedures based on commonly agreed principles be followed and that approval be gained from a recognised body. The Social Research Association (SRA), for example, makes it clear that, in undertaking social research, the responsibility of the researcher:

...entails thinking about the consequences of one's actions upon others and the establishment of clear lines of accountability for the redress of grievances. (2003, p. 7)

Also that:

Social researchers must strive to protect subjects from undue harm arising as a consequence of their participation in research. (p. 14)

The SRA also states that: 
Social researchers have a moral obligation to attempt to minimise the risk of physical and/or mental harm to themselves and to their colleagues from the conduct of research. Research managers may, in addition, have a legal obligation in terms of health and safety regulations to ensure that risk to field researchers is minimised. (p. 24)

Denscombe elaborates the latter point further:

Research must not cause pain or distress to those being researched, and there is duty on social researchers to think ahead and foresee any aspects of involvement with the research that could potentially cause mental stress or physical discomfort. Where appropriate, participants can be debriefed after their involvement to put their minds at rest about aspects of the research that might leave them worried. (2002, p. 179; our emphasis)

Arguably, members of the public invited into participation activities such as the Reference Group should be regarded in the same way as members of the public invited to participate in research. While risking the charge of ageism, it might also be argued that older people (at least some of them) by dint of physical and/or mental frailty are perhaps at greater risk of harm when participation activities develop problems of the sort evident in the Reference Group* especially if the participants are left with a feeling of having let other older people down. One could possibly argue that what distinguishes participation in research from participation in forms of deliberative democracy is that the latter activity is, by definition, political and that politics is a 'rough trade'. In other words, when someone voluntarily enters the public sphere in this way they have to accept that this carries with it the likelihood of struggle, conflict and the possibility of failure. To some extent, this is true. However, the participation agenda implies and promises new forms of democratic activity that go beyond the traditional party political, adversarial model. The new system is supposedly designed to promote inclusion and the revival of civic duty, moving away from a system which excludes all bar accomplished 'political animals'. If inclusiveness is an important goal, then the role of the 'involved citizen' needs to be reconceptualised.

Because involved citizens are not research subjects, no formal ethical guidelines apply. Also, because they not employees, voluntary 'involvees' are not protected by employment, health and safety or contract law. Nevertheless, such people are undertaking activities that may leave them exposed to risk of harm* mainly of emotional distress. It seems self-evident that bodies using older people in this way have a duty of care to protect them from unnecessary stress. Whilst it is tempting to formalise such arrangements through contracts and other formal agreements, it must be acknowledged that too large a dose of formal contractualism may put people off participating in the first place, which is counter-productive. The ethical stance adopted by an organisation that wishes to involve the public need not be informed by utilitarianism or rational-legalism in order to be effective. It might be that an approach guided by 'ethic of care' principles could be more suitable. That is to say that, rather than take an approach to risk which is based heavily on rational calculations of harmful outcomes with a form of caveat emptor warning given to would-be participants, the approach should be more informed by the ethics of care (Meagher \& Parton 2004; Held 2005; Lloyd 2006; Mackin 2005). Here, the emphasis is on the importance of interpersonal relationships, feelings and emotional commitments between people. However, such an approach should not simply be seen as being compassionate or 'caring' for its own sake. For, as Lloyd explains:

It is important to bear in mind the observation of feminist ethicists about the centrality of care to all human life. The ethics of care is a form of political ethics, in which an enriched notion of social justice can be achieved through awareness of social practices and the ways in which these are influenced by power. (2006, p.1179)

Whilst the involvement of people in decision making about services that affect them is important, it is not enough to involve thoughtlessly and unfeelingly, nor in ways that are blind to imbalances in power created by institutional and structural factors. Involvers should show that they care for those that they seek to involve and take appropriate steps to ensure their well-being throughout the process. Mackin states: 
Morality and justice...are not exhausted by impartialism, and they must at least be complemented (or replaced, as some theorists argue) by an ethics of attachment, empathy, and responsiveness to the concrete needs of particular others. $(2005$, p. 3)

Using this approach to ethical involvement, not only must involvers think through the processes of involvement and their consequences with some rigour but also some acceptance of a degree of nurturance is also implied. Involvement should not simply be regarded by involvers as an instrumental activity; they should take the opportunity to foster growth $^{*}$ in terms of self-worth ${ }^{*}$ for those that they involve. Certainly, writers such as Held (2005) have argued that the successful renewal of civil society has a better chance by utilising an ethics of care approach. Therefore, when participation activities, such as the Reference Group, are set up, they need to recognise the value of building mutual respect, trust and nurture into the process. Participants need to be given tasks that they are clear about, that are within their capabilities and where they can have a clear sense of what impact their efforts have made. To judge the worth of such activities by their outcomes alone, or by the fact that they took place in the first place, is, it is argued, unethical.

\section{Suggestions for Ethical Guidelines}

On reflection, it is felt that adopting the following nine precepts would have helped make the experience of the Reference Group more positive* even if the outcome had remained the same. They are, to a degree, informed by ethical guidelines used in research governance and by principles based on the ethic of care. We feel that such guidelines could be applied or adapted for similar involvement activities:

(1) Before involvement. Clarification of role must take place, at both individual and group levels. Participants must be sure about what they are exactly signing up for.

(2) For the group. There should be clarity on remit and expectations, including how much power (and therefore responsibility) the group is to have. It is important that the role/remit/purpose of the participation exercise is clarified. Therefore, the exact role of the group/forum/panel/exercise, etc. must be clear. Attention to language used to describe the activity is important. Is it, for example, decision making* does it carry with it certain powers and therefore accountability? Can it spend money? Who is it accountable to? Does it feed into some other part of the system* if so, how? Is it more of a sounding board? Is it an advisory body or a steering group? Is the involving organisation free to ignore any advice or must it be bound by what involvees say? How are differences resolved? Who has the final say? Who keeps a check on this and ensures 'fair play'? Is it some form of campaign or cause group* in which case on what terms and exactly what are the objectives? Is everybody clear what the cause is? Whatever the stated purpose, every attempt should be made to clarify the relationship between involver and involvee. How will participants know if the group is doing what it is supposed to do, is being successful or effective and that everyone is playing their role appropriately? Various other group ground-rules also need to be established. For example, can participants be 'gagged', i.e. stopped from talking to the press? What other rules must be followed? What happens if someone goes seriously 'off piste'? In other words, how can group discipline be maintained?

(3) Establish the degree of formality, ensuring that all perspectives can be included. In agreeing the terms of reference, consideration needs to be given to formal questions such as whether the group members are expected to meet at a certain frequency or whether written notes or minutes should be kept. Similarly, questions such as what the arrangements are for joining or leaving the group and what, if anything, constitutes quoracy for the group. Some guidance also needs to be given on how much time the participants are expected to invest in the exercise. More difficult might be the question of how participants can establish not only the group's lifespan but also emotional boundaries.

The degree of formality will vary according to the purpose and needs of the group. However, establishing the degree of formality is important because above it was suggested that the formalities of traditionally run public meetings allow some people to feel more 'at home' than others in participation activities. Structural factors such as social class, gender or ethnicity, 
either individually or in combination, may disadvantage certain groups. Commentators on ageing also observe that divisions within the life course itself* for example between those in the third age and the fourth age* are important to acknowledge, in order that a 'third age voice' does not end up speaking for a 'fourth age constituency' (Gilleard \& Higgs 1998, 2000). Involvers need to make every effort that participants' habitus and socio-structural situatedness in general are taken into account when facilitating such events. The articulate, white, middle-class participant is just one perspective of many. Therefore, the challenge is how to strike the balance between formality and the inclusion of diverse opinions expressed in, perhaps, more unconventional ways. As indicated below, this will affect how much ongoing support and 'nurture' certain participants receive.

(4) Arranging necessary guidance, support and/or mentoring. The need for clarity of role, purpose and powers has been a key theme emerging from the case study. It therefore behoves involvers to consider selection processes in order to take account of a diversity of constituencies. Individuals cannot be expected to represent perspectives other than their $\mathrm{own}^{*}$ at least not without adequate support to undertake research etc. Not only would this raise questions about the legitimacy of their mandate but it would also place them in an impossible situation which might be stressful.

Depending on the exact nature of the activity, it is worth considering having an independent chair or guide to support the group. This would help with group discipline and focus, and deal with some of the issues about establishing the most appropriate degree of formality. In this vein, were it to be possible, involvers might also want to consider the possibility of offering mentoring. This might help participants feel more competent and therefore more confident in discharging their responsibilities.

(5) For individual participants. Similar questions need to be addressed at the level of the individual participant. For example, what exactly is expected of an involvee? Are they there to give individual views and opinions? Are they expected to canvass views from others, and if so, whom? Should they discuss and exchange views with others? Should they attempt to achieve a group view? In cases where there is no consensus achieved, how can dissent/ conflict be represented? Should they work individually or collectively?

(6) Welcome. Participants should be 'greeted' and made to feel both welcomed and validated. An acknowledgement of time given should be made. Greeting should include offering refreshments to those taking part. Involvers should adopt an overall stance that is businesslike but also nurturing, that is patient and polite and able to facilitate different personalities working together. Clarification of role expectations needs to be ongoing. A safe environment needs to be created whereby it is possible for people to ask what they might feel are silly questions or raise queries. Clearly, it needs to be established whether individuals have any communication problems* a loop system might be required, for example. Similarly, it might be necessary to consider the use of advocacy/interpreters in certain circumstances. Locations obviously need to be fully accessible. There is an obvious benefit in both involvers and participants sitting down at the start and negotiating jointly what the exact terms of reference are.

(7) Ongoing support. This is important for maintaining the focus and keeping to the task, but also for ensuring inclusion, helping to manage conflict and providing ongoing nurture, attending to bruised egos and so on. It might require some form of mentoring or the use of a facilitator/guide who can help with logistical support and any research, statistics or other data needed to help the participants make an informed decision. Also, assistance needs to be provided with practical facilities such as meetings rooms and transport. Importantly, the clarification of purpose and ground-rules should be ongoing, in order to avoid 'mission creep'.

(8) Attending to endings. It is clearly important to allow participants to have a sense of their role being complete and their task finished* whatever the outcome. Consideration should be given to offering support or debriefing at the end to participants, as they may feel the need to discuss experiences, thereby acknowledging the impact that such an experience has on people, their lives and their identity. A clear, positive ending should also involve thanking and acknowledging everybody's input. An explanation should be given of any arrangements for 
feedback and follow up. With these arrangements in place, it should be possible to minimise, if not totally eradicate, unwelcome feelings such as being 'left high and dry', morbid ruminations, bitterness and so on. Establishing what participants' needs are post-involvement, again, will vary from group to group.

(9) The 'involver' should lay their cards on the table. In her explication of the concept of care, Tronto (1993) stresses the importance of 'integrity'. This should prompt involvers to be candid, from the start, about what they understand the power relationship to be between themselves and those they seek to involve. Above, we used the concept of Arnstein's 'ladder' to represent the range of power relationships that can exist in participation activities. Ethical involvement is more likely to take place if the involver is open about the precise nature of the relationship and where they see power lying. In this way, those involved would not only avoid having their expectations raised unnecessarily but it would also help to clarify issues of accountability and responsibility. Where more tokenistic forms of involvement were expected, it would allow involvees either to withdraw or attempt to renegotiate their position rather than go along in a state of uncertainty.

\section{Conclusion}

Today, it is increasingly likely that members of the public, either as users of a particular service or as citizens in a particular age group, can expect to be invited to become involved in some form of participation activity. The justification for this is usually couched in terms of user-empowerment, putting people in control and so on. This case study shows that, even with the best of intentions, experiences of involvement can turn out to be negative. This reflects a certain degree of naivety on behalf of the voluntary organisation, believing that the very act of involvement itself was a good thing and an end in itself. The organisation had failed to think through the likely impact on the members of the Reference Group. It had also, crucially, failed to make clear what was expected of members either as a group or as individuals in that group. As a consequence, individuals put in a considerable amount of effort, but, nonetheless, had a sense of failure that stayed with them well beyond the life of the group. The fact that the group was never formally terminated and the participants' contributions were not fully acknowledged contributed to this unwelcome situation. Given the current prevailing desire to involve service users at every opportunity, it is unlikely that such experiences are not being replicated, to some degree, around the United Kingdom and further afield. This paper, therefore, is written as a cautionary note to involvers. On a more positive note, it suggests that the ethical principles adopted in social research could be employed to ensure that participation exercises are undertaken in ways that are inclusive, empowering and offer opportunities for growth, and safeguard participants against exposure to emotional distress.

\section{References}

Arnstein, S. R. (1969) 'A Ladder of Citizen Participation', Journal of the American Institute of Planners, Vol. 35, no. 4, pp. 216_24.

Barnes, M. (2005) 'The Same Old Process? Older People, Participation and Deliberation', Ageing \& Society, Vol. 25, no. 2, pp. 245_59.

Barnes, M., Newman, J. \& Sullivan, H. (2007) Power, Participation and Political Renewal: Case Studies in Public Participation, Policy Press, Bristol.

Beresford, P. (2001) 'Participation and Social Policy: Transformation, Liberation or Regulation?', Social Policy Review, no. 14, pp. 265_90.

Bourdieu, P. (1984) Distinction: A Social Critique of the Judgement of Taste, Harvard University Press, Cambridge, MA.

Cabinet Office (2005) http://www.archive.cabinet-office.gov.uk/servicefirst/1998/op/newop.htm (accessed 24 June 2008).

Callaghan, G. \& Wistow, G. (2008) Can the Community Construct Knowledge to Shape Services in the Local State?', Critical Social Policy, Vol. 28, no. 2, pp. 165 _ 86.

Cooper, C. \& Dewe, P. (2004) A Brief History of Stress, Blackwell, Oxford.

Counsel and Care (2007) Real Choice, Real Voice: Older People in Control, Counsel and Care Policy Discussion Paper 2, London Counsel and Care, London. 
Denscombe, M. (2002) Ground Rules for Good Research, Open University, Buckingham. Fairbrother, K. \& Warn, J. (2003) 'Workplace Dimensions, Stress and Job Satisfaction', Journal of Managerial Psychology, Vol. 18, no. 1, pp. 8_21.

Fontana, D. (1989) Managing Stress, Routledge, London.

Gilleard, C. \& Higgs, P. (1998) 'Old People as Users and Consumers of Health Care: A Third Age Rhetoric for a Fourth Age Reality?, Ageing \& Society, Vol. 18, no. 2, pp. 233 49.

Gilleard, C. \& Higgs, P. (2000) Cultures of Ageing: Self-citizen and the Body, Prentice Hall, London.

Glaser, B. G. \& Strauss, A. L. (1967) The Discovery of Grounded Theory: Strategies for Qualitative Research, Aldine De Gruyter, New York.

Gwent Association of Voluntary Organisations (2007) Caerphilly 50_Forum Digital Lobbying, available at: $h t t p: / / w w w . w l g a . g o v . u k / d o w n l o a d . p h p ? i d=1540 \& \mathrm{l}=1$ (accessed 17 November 2008).

Held, V. (2005) The Ethics of Care: Personal, Political, and Global, Oxford University Press, Oxford.

Lewis, J. \& Ritchie, J. (2003) 'Generalising from Qualitative Research', in Qualitative Research Practice, eds J. Ritchie \& J. Lewis, Sage, London, pp. 263_ 86.

Lloyd, L. (2006) A Caring Profession? The Ethics of Care and Social Work with Older People', British Journal of Social Work, Vol. 36, no. 7, pp. 1171_85.

Mackin, G. (2005) 'On the Conceptual Relation between Care and Deliberative Democracy', paper presented at the American Political Science Association annual meeting, Washington, DC.

Meagher, G. \& Parton, N. (2004) Modernising Social Work and the Ethics of Care', Social Work and Society, Vol. 2, no. 1, pp. 1027.

Postle, K., Wright, P. \& Beresford, P. (2005) 'Older People's Participation in Political Activity* Making their Voices Heard: A Potential Support Role for Welfare Professionals in Countering Ageism and Social Exclusion', Practice, Vol. 17, no. 3, pp. 173 89.

Potter, J. (1996) Representing Reality: Discourse, Rhetoric and Social Construction, Sage, London.

Simmons, R. \& Birchall, J. (2005) 'A Joined-up Approach to User Participation in Public Services: Strengthening the "Participation Chain"', Social Policy \& Administration, Vol. 39, no. 3, pp. 260_83.

Social Research Association (2003) Ethical Guidelines, December 2003, London: Social Research Association.

Tetley, J., Haynes, L., Hawthorne, M., Odeyemi, J., Skinner, J., Smith, D. \& Wilson, V. (2003) Older People and Research Partnerships', Quality in Ageing, Vol. 4, no. 4, pp. 18 23.

Tronto, J. (1993) Moral Boundaries: A Political Argument for an Ethic of Care, Routledge, London.

United Nations (2009a) http://www.un.org/ageing/un principles.html\#Participation (accessed 8 January 2009).

United Nations (2009b) http://www.un.org/ageing/iyop highlightsa.html 